\title{
HABITAÇÃO E PERIFERIA: O PROGRAMA MINHA CASA MINHA VIDA
}

Rosa Maria Locatelli Kalil

Universidade de Passo Fundo

kalil@upf.br

\author{
Adriana Gelpi \\ Universidade de Passo Fundo \\ agelpi@upf.br
}

\author{
Jaqueline Becker Fengler \\ Universidade de Passo Fundo \\ 141900@upf.br
}

\section{RESUMEN}

A política habitacional brasileira do Programa Minha Casa Minha Vida têm produzido significativo número conjuntos habitacionais de interesse social por todo Brasil. A maioria destes conjuntos tem se localizado em áreas de expansão urbana, como tecidos urbanos distantes do centro dos consolidados. $O$ trabalho aborda estudo de caso em Passo Fundo (RS), em conjunto habitacional que associa investimentos públicos e privados, tendo como característica a diversidade de tipologias habitacionais, tecnologia construtiva racionalizada e a gradual oferta de equipamentos comunitários. A pesquisa trabalha métodos e conceitos de valoração integral das áreas habitacionais propostos por Montaner, Muxi e Falagan (2011). Como resultados, verifica-se que mesmo em empreendimentos habitacionais privados, as ferramentas de "habitar o presente", que compreendem a habitação como parte integrante do urbano e contribuem para que a construção do território seja feita com qualidade e sustentabilidade.

Palabras clave: 1; plano diretor 2; estatuto da cidade, 3; morfologia urbana e sustentabilidade

\section{ABSTRACT}

The housing policy of the Minha Casa Minha Vida Program has produced significant number of low-income housing across Brazil. Their majority has been located in urban expansion areas as urban mesh, which are distant from the center of the consolidated ones. This work approaches a study case in the city of Passo Fundo (RS), in low-income housing that associates public and private investments, whose characteristic is the diversity of housing tipologies, innovative technology and the gradual offer of community equipments. This research works appreciation methods and concepts of housing areas proposed by Montaner, Muxi and Falagan (2011). As results, it is verified that even in private housing businesses, the tools of "inhabit the present", that understand housing as integral part of the urban, contribute so that the construction of the territory is carried out with quality and sustainability.

Key-words: 1; master plan 2; city statute, 3 ; urban morphology and sustainability. 
As recentes políticas públicas para habitação de interesse social, no Brasil, têm criado uma paisagem de novos condomínios e loteamentos nas periferias das cidades brasileiras. A morfologia urbana das periferias se reconstrói, ao espaço informal somam-se conjuntos padrão de unidades habitacionais repetitivas. A forma urbana produzida intencionalmente afasta o singular e o inesperado da autoconstrução, pretendendo padronizar e atender demandas reprimidas numa questionável e massiva reprodução de guetos de moradias, mas não de pertencimento às cidades.

Verifica-se, desta forma e de acordo com Maricato (2011) que apesar das críticas ao processo da construção das habitações de interesse social implementadas no país, no final do século XX, as dimensões, a uniformidade e o distanciamento das facilidades urbanas tem se repetido. Neste contexto, à periferia das cidades é agregada uma massa edificada de habitações unifamiliares ou multifamiliares uniformes e monótonas instaladas em grandes áreas monofuncionais.

Na cidade de Passo Fundo, Rio Grande do Sul, repete-se o processo, mas o conjunto habitacional em estudo diferencia-se dos demais por estar localizado numa área de expansão legal da cidade, prevista em seu Plano Diretor de Desenvolvimento Integrado (2006) e por apresentar tipologias habitacionais variadas, sistema construtivo diferenciado em relação às construções padrão dos programas habitacionais convencionais e por abrigar frações sociais diferenciadas em suas moradias.

Num município que apresenta crescimento populacional positivo, estes elementos pressupõem uma diferenciação na construção de novas paisagens urbanas, pois o loteamento e o conjunto habitacional analisado se encontram numa área de expansão da cidade, uma parte da cidade em construção, sendo dotada de relativa infraestrutura e equipamentos urbanos.

\subsection{Definição do tema}

O trabalho aborda a formação de novas paisagens urbanas a partir da implantação de núcleos habitacionais de interesse social em áreas periféricas de cidade média brasileira. Estudos realizados por Maricato (2011), Bonduki et al. (2012) e por pesquisadores de todo o Brasil, avaliam a dinâmica da política habitacional a partir da implantação do Ministério das Cidades, da retomada de financiamentos habitacionais e de desenvolvimento urbano. Ressaltam a dificuldade de avaliar a efetividade dos mesmos na redução do déficit, na qualificação do hábitat e na continuidade dos programas, devido à diversidade das situações no território, pela insuficiência de estruturas administrativas e operacionais confiáveis e independentes de gestões políticas em todos os entes federados.

O grande déficit habitacional brasileiro que busca ser coberto pelos programas habitacionais, havendo investimentos públicos e privados, faz com que a questão da quantidade de moradias sempre seja priorizada em relação à qualidade de moradias. Mesmo após séculos de oferta irregular, a evolução dos programas sociais não resolveu a questão da precariedade das habitações ofertadas (Siqueira e Araújo, 2014). Mesmo a criação do Estatuto da Cidade e do Programa Minha Casa Minha Vida, embora tenha trazido nova expectativa à questão habitacional, parece ter dificuldade em propiciar a qualidade merecida pela população de baixa renda (Moreira e Pina, 2012). Estudos sobre a pobre condição da arquitetura e da localização urbana em habitações sociais no Brasil, conclui o quanto afetam os habitantes desses empreendimentos. Apesar disso, as pessoas buscam adaptar suas moradias, reinventando os modos de habitar e sobreviver de acordo com suas necessidades (Villa et al. 2017).

O programa Minha Casa Minha Vida (MCMV) foi um marco na política habitacional por destinar um alto volume de subsídios diretos, destinados ao comprar e priorizando famílias de menor renda, conforme previsto no Plano Nacional de Habitação. As famílias com até três salários mínimos de renda (faixa 1) receberam subsídios mais elevados, e as de três a seis subsídios decrescentes (faixa 2), conforme a renda. Também as de renda familiar de seis a dez salários mínimos (faixa 3) foram beneficiadas com redução de juros e outros benefícios. Em relação a projetos anteriores, houve estiramento exagerado das faixas de renda, beneficiando segmentos da classe média, e gerando mercado para o setor privado. $\mathrm{O}$ alto volume de subsídios diretos à moradia é a espinha dorsal do MCMV, tornando a política incerta, pois a suspensão dos subsídios paralisará todo o sistema em seu entorno (Meyer, 2014: 117).

Mesmo com subsídios e benefícios previstos houve muita dificuldade em viabilizar projetos nos principais centros urbanos, principalmente nas metrópoles, devido à escassez de terrenos integrados às cidades e, 
consequentemente, seus preços estariam inviabilizando os projetos. Desacompanhado de políticas urbanas e pautado basicamente por critérios de viabilização financeira, o MCMV induz os agentes a procurarem terrenos baratos e distantes, reproduzindo o antigo modelo do BNH e Cohabs, os quais produziam grandes conjuntos há horas de distância dos centros das cidades e dos empregos. (Meyer, 2014: 121-122).

Segundo Shimbo (2012) ao analisar o papel das empresas construtoras nesse processo, "a produção das cidades no Brasil se alterou profundamente neste início do século XXI. Num período de cinco anos, sobretudo entre 2006 e 2010, grandes empresas construtoras e incorporadoras passaram a ofertar habitação para as camadas de baixa renda da população imprimiram um ritmo acelerado na verticalização e no espraiamento dos tecidos urbanos".

Mesmo assim, observa-se maior exigência do programa e da Caixa Econômica Federal em relação à inserção e qualidade urbana. Meyer (2014) aponta que os projetos apresentados devem contemplar questões urbanas locais do empreendimento: transporte, iluminação, coleta de lixo, abastecimento de água e energia, solução de esgotamento e inserção na malha urbana. No MCMV 2 incluiu-se a exigência da provisão de drenagem pluvial, vias de acesso e circulação pavimentadas, calçadas, guias e sarjetas, além da "adequação ambiental do projeto". Quanto à localização restringe a exigir a "localização do terreno na malha urbana ou em área de expansão que atenda aos requisitos estabelecidos pelo Ministério das Cidades, observado o respectivo Plano Diretor, quando existente", e a exigência ou compromisso do poder público local de instalação ou de ampliação dos equipamentos e serviços relacionados à educação, à saúde, ao lazer e ao transporte público. "De qualquer forma, ao deslocar a população para locais distantes esse modelo satura o sistema viário, degrada o meio ambiente e segrega os moradores socialmente, de forma a dificultar o acesso às oportunidades de emprego e de serviços, o que configura a maior fragilidade do MCMV" (Meyer, 2014).

A construção de novas paisagens urbanas constituídas por conjuntos habitacionais de tipologias diferenciadas pode ser documentada em pesquisas realizadas por Kalil et al. (2014).Os autores registraram que os novos projetos de conjuntos habitacionais de interesse social seguiram a política nacional com foco em projetos de caráter local, em núcleos de menor porte, financiados com recursos federais com uma contrapartida municipal (Brasil, 2012). Nesse contexto, vários núcleos foram construídos em Passo Fundo com tipologia de unidades térreas isoladas, geminadas e tipologia de unidades multifamiliares de quatro ou cinco pavimentos. (Kalil, 2003; Sobarzo, 2010, Kalil et al., 2014).

Em Passo Fundo, cidade média do norte do Rio Grande do Sul, Brasil, nas décadas de 2000 a 2012, os programas habitacionais de interesse social passaram a ser realizados pelo governo municipal com aporte de recursos federais e contrapartida local, sendo executados por empresas construtoras privadas. No Programa Minha Casa, Minha Vida os conjuntos mais recentes estão recebendo urbanização mais completa, como sistema viário e passeios pavimentados, iluminação pública e equipamentos comunitários nas proximidades.

A localização dos empreendimentos habitacionais geralmente tem sido nas regiões periféricas da malha urbana, ou em glebas vazias desprovidas de infraestrutura urbana. Tal situação dificulta a inserção urbana e por consequência a inserção social dos moradores na dinâmica da cidade. Considerando que a distância da área central requer dispêndio de tempo e recursos para a mobilidade para os espaços de trabalho, de lazer e de equipamentos comunitários, mesmo atendendo a provisão da moradia específica, os demais requisitos não são contemplados nos projetos (Figura 1). 


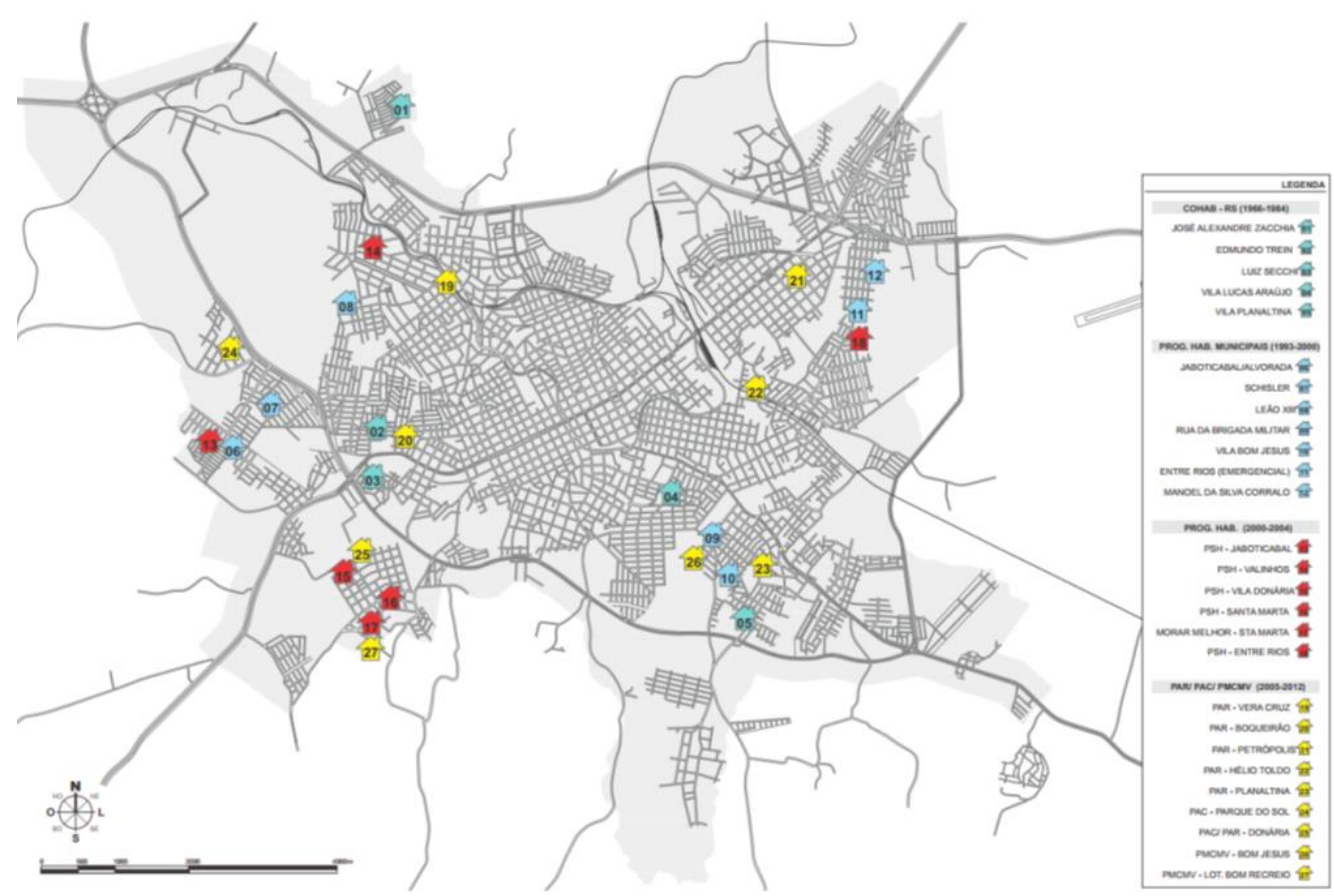

Figura 1: Localização dos projetos habitacionais de interesse social em Passo Fundo (1996-2012) Fonte: Elaboração própria dos autores

\subsection{Caso de estudo: Jardins Nativos}

O objeto da pesquisa é o conjunto habitacional denominado Jardins Nativos, programas habitacionais de interesse social do programa Minha Casa Minha Vida, localizado na Vila Donária, Setor 8 - Bairro Santa Marta, em área periférica e distante cerca de $6 \mathrm{~km}$ do centro da cidade de Passo Fundo. Nesta área está prevista a expansão urbana e a densificação habitacional, de acordo com o Plano Diretor de Desenvolvimento Integrado (2006) e plano urbanístico municipal (2012) aprovado pelo Banco Interamericano de Desenvolvimento. Nesta área localizam-se os empreendimentos habitacionais mais recentes e que apresentam diferenciais quanto às tipologias habitacionais e às tecnologias construtivas executadas em loteamentos convencionais.

O Setor 08 conta com uma área de $5,61 \mathrm{~km}^{2}$, constituindo-se assim uma área de expansão urbana, sendo que em 2010 contava com uma população de 5.355 habitantes e uma densidade demográfica de 954,55 $\mathrm{hab} . / \mathrm{km}^{2}$ (lbge, 2010). Este setor está recebendo investimentos de plano urbanístico municipal, sendo prioritário para a implantação de empreendimentos sociais. Nele foram implantados diversos projetos habitacionais denominados Vila Donária (2010 e anos anteriores). Contudo, ainda são poucos os equipamentos urbanos existentes: escola de ensino fundamental e médio, escola de educação infantil, unidade de saúde, centro de assistência social, capelas e comércio de pequeno porte. O setor não apresenta áreas verdes públicas, nem equipamentos públicos de lazer ou esporte, apenas alguns clubes privados.

O Condomínio Jardins Nativos vem sendo implantado desde o ano de 2012 sendo subdividido em 17 condomínios fechados, que contarão cada um com 24 unidades habitacionais, em diferentes modalidades (isoladas, térreas geminadas, sobrados de apartamentos), e que serão financiadas através de uma parceria entre a Prefeitura Municipal e a Caixa Econômica Federal por meio do Programa Minha Casa Minha Vida. Está localizado em área de 40 hectares, delimitada pelas as ruas Dona Georgina Schell, Muçum e Miguelzinho Vargas, na parte sudoeste do bairro, com área de preservação a oeste. A área foi designada como Zona Especial de Interesse Social em legislações de 2009, 2010 e 2011.

\section{METODOLOGIA}

O trabalho está encaminhado, tendo-se como base, de acordo com Werna (2001), uma metodologia que combina a avaliação do produto - neste caso, a unidade habitacional e seu coletivo, com uma avaliação do processo, que inclui uma análise dos mecanismos institucionais utilizados pela municipalidade, ou seja, os programas adotados, suas implantações nas áreas urbanas, e a avaliação dos atores sociais envolvidos na aquisição da habitação. 
Após a caracterização geral do conjunto habitacional será avaliado sua inserção urbana, entendendo-se por inserção urbana a forma com que o conjunto e as unidades habitacionais unifamiliares e multifamiliares se articulam no e com o espaço urbano, considerando-se sua localização, a sua adequação ao entorno, as suas conexões com as infraestruturas e o atendimento por serviços públicos.

Procurando uma revisão de critérios de projeto da habitação coletiva no século XXI, Montaner e Muxi (2010) promovem uma série de questões-chave: a habitação responde à diversidade da sociedade? Contribui para melhorar a qualidade da cidade e do território? O uso razoável é feito de tecnologias disponíveis? Responde aos objetivos de sustentabilidade? Os parâmetros de trabalho em proposta de valoração integral, de $14+1$ variáveis permitem projetar e avaliar projetos. Em conclusão, a qualidade da moradia resulta tanto da resolução correta do seu interior, quanto no contato com o espaço público do bairro, através de uma diversidade de gradientes que vão do urbano ao privado.

$\mathrm{Na}$ análise do conjunto habitacional serão aplicados os métodos e os conceitos básicos de valoração integral das áreas habitacionais propostos por Montaner, Muxi e Falagan (2011), no que se refere à teoria de "Habitar o presente", onde os autores refletem sobre a unidade habitacional num contexto contemporâneo de grandes transformações sociais, culturais e tecnológicas agrupando uma série de questões em quatro grandes áreas: 1) sociedade, 2) cidade, 3) tecnologia e 4) recursos.

Em relação à Sociedade (1) contemporânea, os autores ressaltam a readequação e diferenciação da composição dos grupos familiares; onde a posição do chefe de família provedor, mãe cuidadora e grande número de filhos deve ser revista e cuja estrutura não é mais rígida e hierarquizada; a residência passa a ser também, um espaço de trabalho e de armazenamento. Observam que os novos padrões sociais contemporâneos requerem tipologias habitacionais diferentes. Pois a heterogeneidade da sociedade atual com distintos níveis de renda, de composição familiar multifacetada, de tipos de ocupação profissional diversificados, de gêneros, de níveis de estudos diferenciados, de estrutura demográfica em transformação e com mudanças endógenas na estrutura dos lares alteram significativamente, as propostas tipológicas e morfológicas, para os conjuntos habitacionais a serem propostos.

Em relação à Cidade (2), os autores questionam a relação da unidade habitacional com o espaço urbano, observando que a habitação deve estar inserida na cidade e não ser um apêndice a ela. Neste sentido, os valores de proximidade; a relação da habitação com espaço público; os espaços de convivência e de usos; assim como os espaços intermediários assumem, talvez, maior importância que a própria unidade habitacional. São potencializados os valores de proximidade, onde os moradores devem realizar o máximo de atividades cotidianas em distâncias percorridas a pé, com trajetos alternativos, podendo escolher entre diversas opções, ter fácil acesso ao transporte público, às compras do cotidiano, à educação, ao trabalho, à saúde, ao esporte, ao lazer a aos equipamentos do bairro. Os autores colocam que a residência deve ser compreendida como "o projeto urbano", ou seja, o projeto residencial deve ser visto como parte de um projeto urbano equilibrado. As unidades habitacionais não podem ser peças autônomas. Quando funcionais devem favorecer a potencialização de redes sociais e comunitárias criando a cidade real sobre as bases de um bom projeto urbano (Montaner, Muxi e Falagan, 2011: 45).

Em relação à Tecnologia (3) os autores abordam a formalização, a adequação tecnológica e das instalações da unidade habitacional. Sugerem a agrupação de áreas úmidas; a adaptabilidade e a qualidade da construção, que deve, necessariamente, abrigar inovações tecnológicas, inserindo a residência numa realidade cada vez mais mutante. Dentro desta realidade, devem ser pensados novos dispositivos, que ofereçam alternativas às estratégias convencionais para uma família tipo. Neste sentido, as respostas projetuais devem ser capazes de adequar-se a um sem número de fatores como a flexibilidade, uma das condições essenciais ao espaço habitável, mantendo uma adequada articulação com os sistemas, as estruturas e os elementos construtivos. Estes elementos, assim como os fechamentos e as instalações devem ser pensados para permitir uma maior evolução e adequação às mudanças dos usuários. (Montaner, Muxi e Falagan, 2011: 51-54).

Os autores sugerem que a estanqueidade do projeto e da edificação não devem se converter em obstáculos para as transformações e adequações da residência às especificidades de cada família, numa sociedade em transformação. Devem então, comportar dispositivos técnicos que possibilitem o crescimento da superfície edificável, possibilitar as modificações internas dos espaços e a fácil atualização das instalações. Esta desejada adaptabilidade e flexibilidade construtiva poderão ser obtidas através do emprego de 
estruturas de grandes luzes, fachadas com repetição equidistante de vazios, a disponibilidade de divisórias leves, de elementos móveis, com maneiras fáceis de reparar ou transformar as instalações.

Abordando a questão dos Recursos (4), os autores propõem a retomada de partidos de projeto quase vernaculares, mas esquecidos em função do emprego das novas tecnologias, do uso da energia elétrica, do ar condicionado, do uso de elevadores, esquecendo o aproveitamento passivo e ativo do clima urbano, a exploração da ventilação cruzada, a eficiência energética, o aproveitamento dos resíduos e a reciclagem dos materiais, dos insumos e da própria energia.

\section{RESULTADOS E DISCUSSÕES}

\subsection{Análise em relação ao quesito Sociedade}

O bairro Santa Marta, no qual se localiza a Vila Donária, é caracterizado historicamente por uma população de renda baixa, tendo iniciado nas proximidades de estação transformadora de energia implantada há cerca de quatro décadas e ao longo da via de acesso a distrito rural. Com moradias muito precárias no início de sua criação, era denominado vila Brasília; após surgiram habitações de baixo padrão, autoconstruídas. 0 bairro contava com reduzidos equipamentos comunitários: escola, capela e instituição de assistência social. Além de loteamentos populares, na década de 2010 passou a receber núcleos de habitação de interesse social, contribuindo para atendimento de famílias de baixa renda vindas de outras áreas da cidade.

O projeto em análise, ao mesclar condomínios para várias faixas de renda, proporciona mescla de frações sociais em função da diversidade socioeconômica. Traz proximidade nas relações comunitárias ao implantar condomínios de tipologias diferenciadas em vizinhanças muito próximas. Propõe a potencialização das redes sociais ao mesclar vizinhanças diferenciadas e espaços intermediários mais qualificados, pois um dos aspectos que diferencia este projeto de outros é a adoção de condomínios com número restrito de unidades habitacionais (Figura 2).

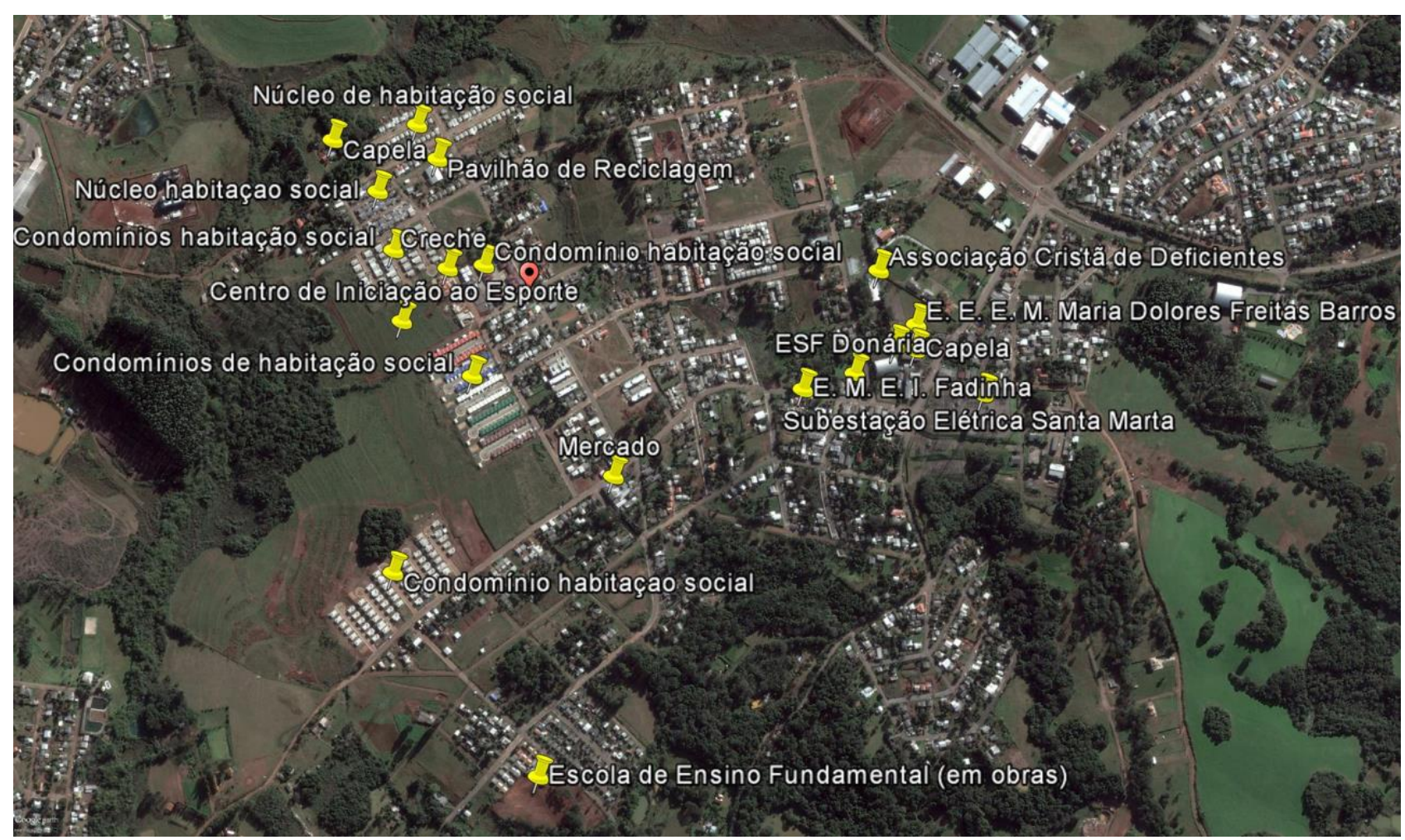

Figura 2: Implantação geral do Condomínio Jardins Nativos (2016)

Fonte: Elaboração dos autores sobre base do Google Maps.

O projeto prevê a construção de cerca de 17 pequenos condomínios habitacionais, sendo que 13 já se encontram construídos e habitados. Foram planejadas três tipologias de condomínios para duas faixas socioeconômicos de população e em conformidade com as possibilidades de financiamento do Programa Minha Casa Minha Vida. A tipologia de casas geminadas, destina-se a população carente, com renda familiar de 0 a 3 salários mínimos, enquadradas na faixa 1 de financiamento (Fig. 2). A tipologia de casas 
isoladas destina-se a população com renda familiar de 3 a 5 salários-mínimos, enquadrados na faixa 2 de financiamento. Da mesma foram as tipologias de apartamentos em pequenos edifícios de 2 pavimentos destinam-se a faixa 2.

\subsection{Análise em relação ao quesito Cidade}

Em relação à cidade, o bairro periférico está sendo integrado ao tecido urbano por meio de projeto urbanístico de qualificação e ocupação populacional, que prioriza a inserção de projetos de habitação social. No entanto, sua localização, entre duas rodovias estaduais de alto fluxo, que formam anel viário que circunda a maior parte da cidade formal, gera limites marcantes, que se somam para dificultar a integração física e social do novo bairro.

O novo conjunto habitacional, mesmo tendo característica monofuncional, está gerando a implantação e a qualificação de equipamentos comunitários, propiciando mais acesso à educação (novas escolas de educação infantil e fundamental em implantação) e saúde (unidade de saúde em funcionamento). A perspectiva de novos moradores com renda um pouco mais elevada deverá trazer novos estabelecimentos comerciais e de serviços.

A pavimentação do sistema viário está sendo realizada por projetos financiados pelo governo federal e evolui acompanhando o processo de construção das moradias. Isto irá facilitar o deslocamento dos moradores para as atividades cotidianas e facilitar o acesso aso transporte público. As vias pavimentadas promovem maior acessibilidade e facilidade ao transporte público. Mas apesar destes diferenciais, constatase que o empreendimento ainda se encontra muito distante das facilidades de um centro urbano consolidado.

Desta forma, este núcleo apresenta aspectos diferenciados em relação a outros projetos realizados no país, e poderá sugerir uma diversificação da morfologia urbana e da mescla social. Merece o acompanhamento do processo de consolidação do bairro para verificar a apropriação do território. Mas esses diferenciais qualificam a proposta.

\subsection{Análise em relação aos quesitos Tecnologia e Recursos}

Por ser projeto que atende aos requisitos do programa de financiamento MCMV, as tipologias seguem com espaços mínimos preconizados pelos editais, ou seja, máximo de 300 unidades por condomínio, casas térreas com mínimo de $32 \mathrm{~m}^{2}$ (Figura 3 e Figura 4), apartamentos com $37 \mathrm{~m}^{2}$. Da mesma forma, têm programa rígido, unidades com dois dormitórios, sala, cozinha, banheiro e área de serviço, sendo maior nos apartamentos que nas casas geminadas ou isoladas.

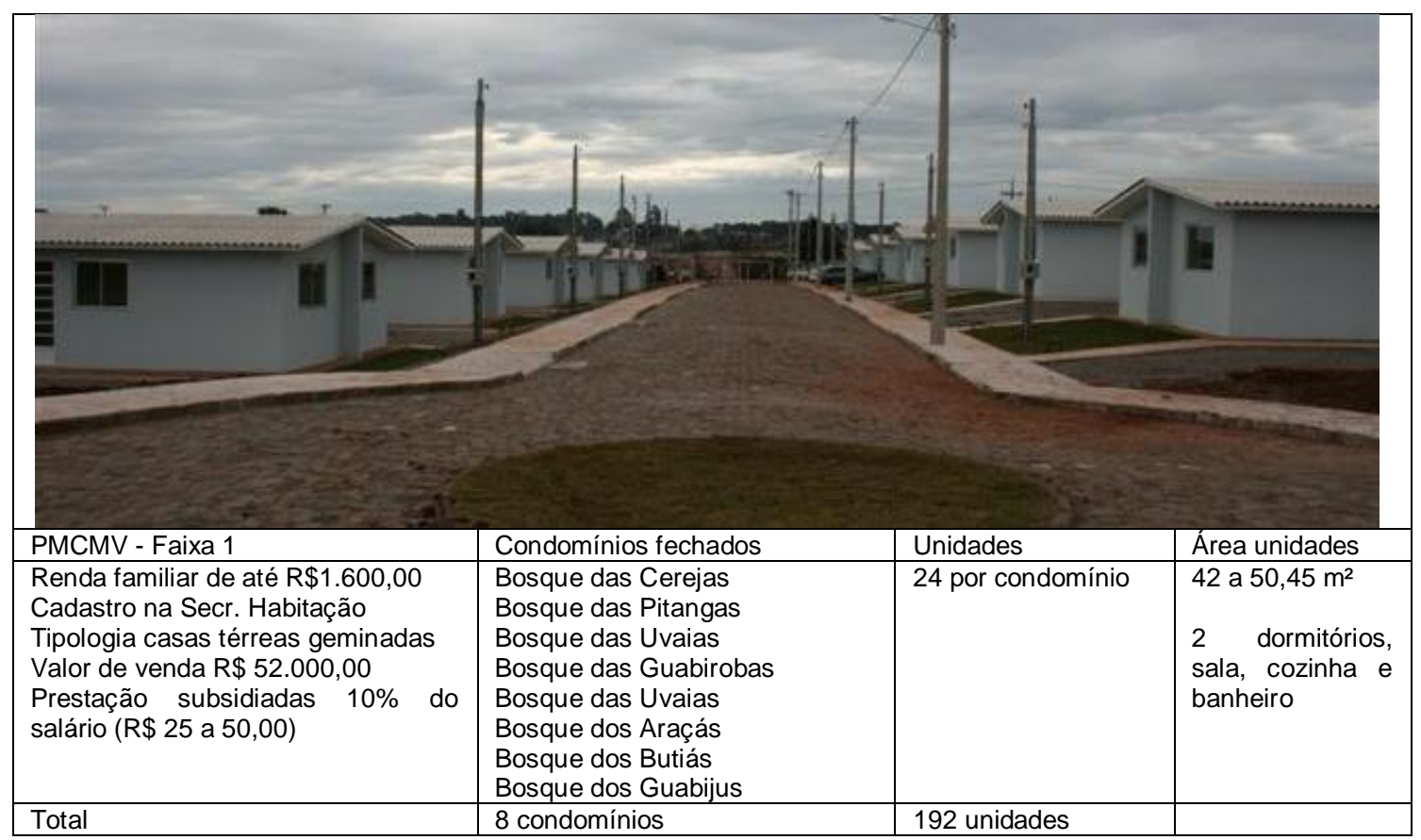

Figura 3: Condomínios Jardins Nativos Faixa 1 - casas geminadas (2012-2015)

Fonte: Acervo dos autores 


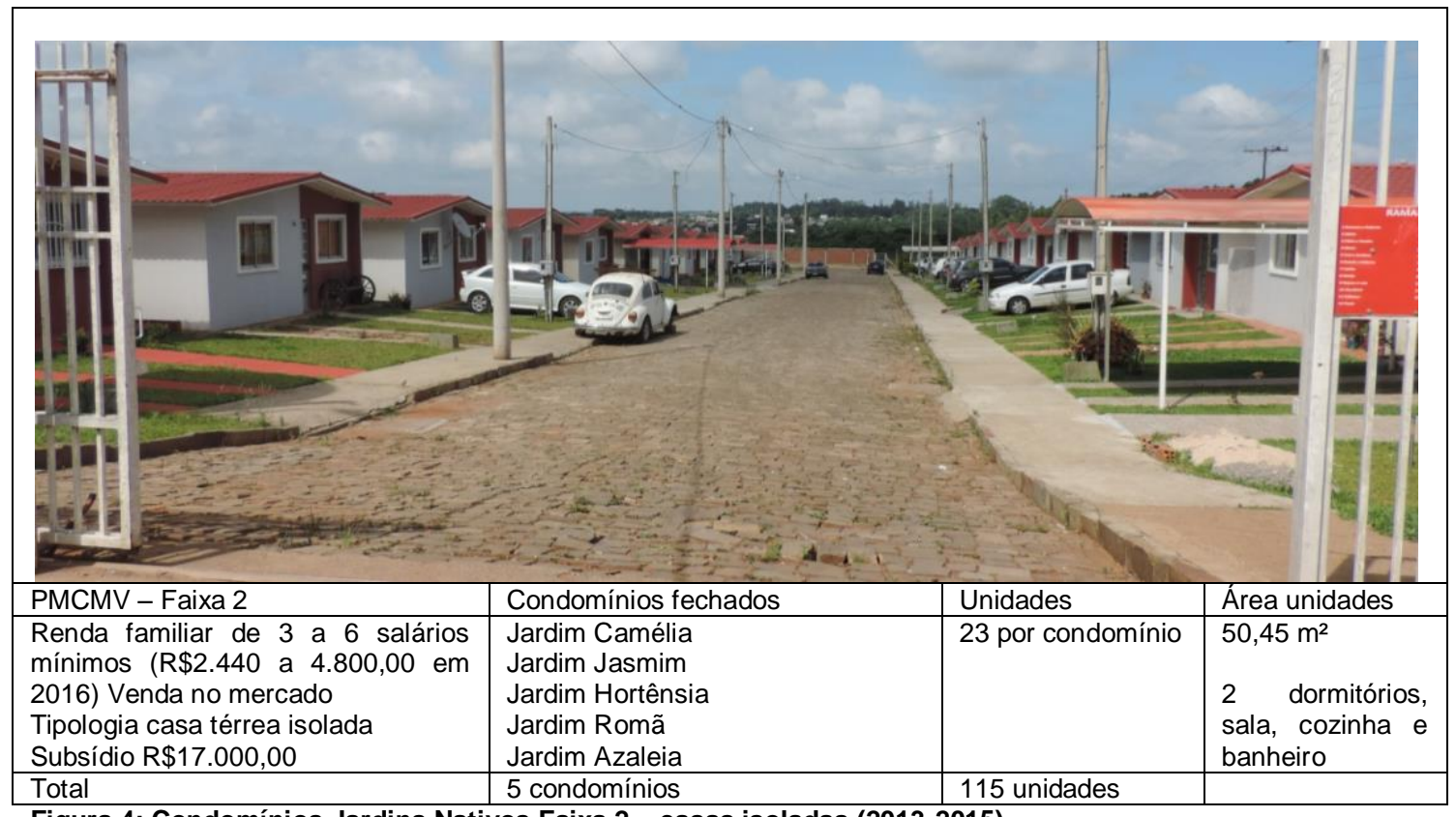

Figura 4: Condomínios Jardins Nativos Faixa 2 - casas isoladas (2013-2015)

Fonte: Acervo dos autores

Os apartamentos apresentam área privativa de $58 \mathrm{~m}^{2}$, mas são distribuídos em pequenos edifícios de dois pavimentos, formando condomínios fechados com salão de festa com churrasqueira e área de playground. As vias internas são pavimentadas com iluminação pública, áreas ajardinadas com estacionamentos e acesso para pedestres e veículos por portões eletrônicos (Figura 4 e Figura 5).

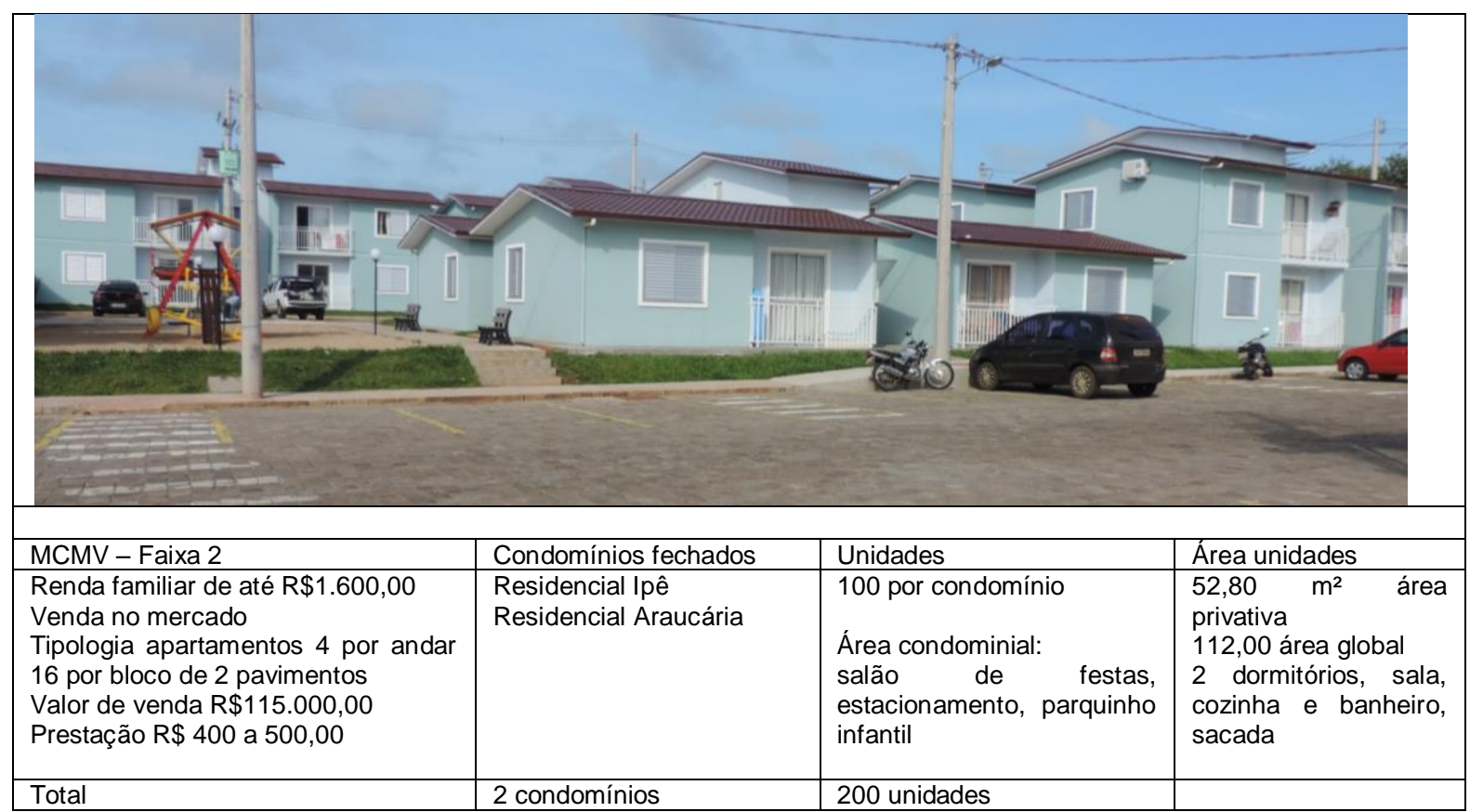

Figura 5: Condomínios Jardins Nativos Faixa 2 - apartamentos, estacionamento, lazer e casas térreas acessíveis (2015) Fonte: Acervo dos autores

A tecnologia construtiva em concreto moldado em grandes formas e cobertura em lajes pré-fabricadas não prevê a possibilidade de ampliação da área ou modificações internas. Por outro lado, oferece vantagens do ponto de vista de isolamento térmico e de acabamento. A racionalidade da obra inicia pela fundação em radier, com concreto reforçado com fibra de aço, instalações embutidas e arranque das paredes, facilitando 
a construção. Instalações hidrossanitárias com kits pré-cortados instalados em negativos no concreto vazado, forro de gesso e laje pré-fabricada, além de outros itens racionalizados.

Os acabamentos com massa texturizada e pintura, piso cerâmico, azulejos sobre chapisco nas áreas molhadas, conferem boa qualidade às moradias. As esquadrias externas de alumínio com veneziana e peitoril de granito, proporcionam ventilação e iluminação natural aos ambientes, reduzindo o uso de energia.

Em virtude das restrições de crédito, os próximos condomínios deverão ter unidades de apartamentos em edifícios de três pavimentos, e serão destinados a faixa denominada preliminarmente de 1,5 , ou seja, em uma adaptação aos requisitos de financiamento e demandas de mercado.

Em relação às singularidades da proposta, o sistema construtivo racionalizado surge como inovação, pois reduz desperdício, acelera o prazo construtivo e resulta em unidade habitacional com melhor qualidade construtiva. Utiliza aberturas com vedações nos dormitórios, orientação solar permitindo iluminação e ventilação natural e materiais com isolamento. As unidades para famílias de baixa renda, ao disporem de dispositivo de aquecimento solar para água, contribuem para a redução de gastos energéticos na demanda e no orçamento das famílias.

\section{CONCLUSÃO}

Em relação ao quesito Sociedade, a utilização de tipologias e de faixas de renda diferenciadas numa mesma área urbana, permite a diversidade de ocupação da área residencial. Os novos padrões sociais contemporâneos requerem tipologias habitacionais diferentes. Mas a rigidez nos ambientes, apenas unidades com dois dormitórios sugeridas pelo órgão financiador, prejudica o atendimento à a heterogeneidade da sociedade atual, de composição familiar multifacetada. Também desconsideram a questão de novas formas de trabalho, que poderiam utilizar espaços anexos aos recintos residenciais para a geração de renda.

Em relação à morfologia urbana analisada no quesito Cidade, verifica-se que o núcleo estudado apresenta uma diversidade relativa, com habitações térreas ou edifícios com poucos pavimentos, resulta em paisagem construída horizontal. Desta forma se incorpora, mas ao mesmo tempo preenche a paisagem existente, de habitações e equipamentos térreos e espraiados. Por ser área de expansão, com vazios urbanos, a morfologia adapta-se ao existente, ao mesmo tempo em que qualifica.

A tipologia adotada de núcleos na forma de condomínios fechados com número de 23 e 24 unidades unifamiliares ou 100 de unidades multifamiliares, embora segmente parcialmente o espaço urbano, parece resultar em melhor manutenção predial e das áreas comuns. Os limites impostos pela vizinhança, e a necessidade de respeito às normas condominiais cria responsabilidades mais definidas em relação à parte da infraestrutura (vias internas, sistema de tratamento de esgoto, áreas livres).

Como singularidade da proposta, além de infraestrutura mais completa em áreas abertas com gramado, vegetação, áreas permeáveis e iluminação pública interna, cada condomínio dispõe de espaços para estacionamento de automóvel próprio, uma nova realidade da população residente ocasionada pelo momento econômico brasileiro e pela opção do veículo particular em detrimento de melhor transporte público. Áreas comuns com espaços para lazer fechado e aberto são outro diferencial, especialmente em um bairro onde inexistem equipamentos comunitários de lazer e esportes.

Em relação às singularidades da proposta nos quesitos Tecnologia e Recursos, o sistema construtivo racionalizado surge como inovação, pois reduz desperdício, acelera o prazo construtivo e resulta em unidade habitacional com melhor qualidade construtiva. Utiliza aberturas com vedações nos dormitórios, orientação solar permitindo iluminação e ventilação natural e materiais com isolamento. As unidades para famílias de baixa renda, ao terem o dispositivo de aquecimento solar para água, contribuem para a redução de gastos energéticos na demanda e no orçamento das famílias.

Ressalte-se que embora entregue para a iniciativa privada, a construção do novo núcleo habitacional teve o compromisso do poder público em realizar a pavimentação das vias, construção de escolas e futura área de lazer. Isto demonstra que o fato de ser a área prevista em legislação urbana municipal para a urbanização de novos bairros facilitou e agregou valor ao espaço urbano, que dispõe assim de pavimentação das vias de pedestre, acessibilidade, a despeito da pouca arborização urbana e nenhuma área verde. No entanto, o bairro em si carece de estabelecimentos de comércio de abastecimento comercial e de serviços diários, 
assim como não dispõe de espaços de trabalho no bairro. Outra grande carência na questão social são os espaços para juventude.

Concluindo, a questão habitar para o presente e a criação de novas paisagens, no caso em estudo, e na maior parte das cidades brasileiras, demandam uma construção participativa. Combinar os interesses privados na apropriação do capital financeiro imobiliário com o atendimento à demanda de habitação social, mesmo sendo contraditório, pode ser viabilizado. Mas requer diretrizes de considerar realmente que o projeto urbano equilibrado é de responsabilidade tanto do poder público quanto do empreendedor privado. E deveria ainda contar com a participação mais efetiva dos moradores no estabelecimento das prioridades para a integração e inclusão urbanas.

\section{BIBLIOGRAFIA}

BRASIL. Ministério das Cidades. (2012). Programas habitacionais. Brasília.

FEE-Fundação de Economia e Estatística. (2012). Passo Fundo. Porto Alegre.

IBGE - Instituto Brasileiro de Geografia e Estatística. (2010). Censo demográfico: 2010. Rio de Janeiro.

KALIL, R. M. L.. (2003). Produção da habitação social em Passo Fundo RS: processo histórico e situação atual. Encontro de Teoria e História da Arquitetura do Rio Grande do Sul, 6. Anais... Passo Fundo. 2003.

(2014) Habitação de interesse social, políticas públicas e desempenho municipal. Relatório da Pesquisa. Passo Fundo: FAPERGS/Universidade de Passo Fundo.

et al. (2014). Políticas públicas de habitação social: panorama em municípios polo da região da produção, RS. XV Encontro Nacional de Tecnologia do Ambiente Construído, Maceió, (1568 - 1577).

MARICATO, E.(2011). Os impasses da política urbana no Brasil. Petrópolis: Vozes

MEYER, J. F. P. (2014) As políticas habitacionais e seus desdobramentos. En: VARGAS, H. C.; ARAÚJO, C. P. de. (Orgs.) Arquitetura e mercado imobiliário. Barueri, SP: Manole.

MONTANER, J. M.; MUXI, Z.; FALAGÁN, D. H. (2011). Herramientas para habitar el presente: la vivenda del siglo XXI. Barcelona: Master Laboratorio de la vivenda del siglo XXI.

Programa do governo federal, Minha Casa, Minha Vida, 2010, O empreendedor, Passo Fundo, v. 1, n. 25, p. 16-17, fev. 2010.

SHIMBO, Lúcia Zanin. (2012). Habitação social de mercado: a confluência entre Estado, empresas construtoras e capital financeiro. Belo Horizonte: C/Arte.

SOBARZO, O. (2010). Passo Fundo: cidade média com funções comerciais, de serviços e de apoio ao agronegócio. En: SPOSITO, M. E. B.; ELIAS, D.; SOARES. B; R; (Org.). Agentes econômicos e reestruturação urbana e regional: Passo Fundo e Mossoró. (29-100). São Paulo: Expressão Popular.

WERNA, E. et al. (2001). Pluralismo na habitação: parceria entre agentes públicos e não públicos. São Paulo: Annablume.

\section{Fuentes electrónicas}

BONDUKI, N.; ROSSETO, R.; GHILARDI, F. H. (2012). Política e Sistema Nacional de Habitação, Plano Nacional de Habitação. 2012. Rio de Janeiro: Instituto Brasileiro de Administração Municipal: Agência Goiana de Habitação. Disponível em: http://www.agehab.go.gov.br/pehis/download/texto\%20 1.pdf . Acesso em: 20 maio 2012.

CONSTRUTORA PRIORI. Jardins Nativos. (2016). Disponível em: http://www.construtorapriori.com.br/ . Acesso em: 27 fev. 2016. 
MONTANER, J.; MUXÍ MARTíNEZ, Z. (2010). Reflexiones para proyectar viviendas del siglo XXI. Dearquitectura, 6, 82-99. Disponível em: https://doaj.org/article/5fb3cbc288ac47c5933ab497a94fe397. Acesso em 01 mar. 2018.

MOREIRA, V. L. B.; PINA, S. M. G. (2012). Mais do mesmo? a trajetória da habitação social no Brasil. Paranoá: Cadernos de Arquitetura e Urbanismo, 6. Disponível em: https://doaj.org/article/07a1a7fe8812463e908df95df6b6a4af. Acesso em: 01 mar. 2018.

PASSO FUNDO. (2006). Plano Diretor de Desenvolvimento Integrado. Passo Fundo. 2006. Disponível em: www.leismunicipais.com.br. Acesso em: 26 fev. 2016.

REIS, A. T. da L.; DIAS, M; C. (2010). O projeto da habitação de interesse social e a sustentabilidade social. Ambiente Construído (Porto Alegre), 10, n. 3, 99-119. Disponível em:

http://dx.doi.org/10.1590/S1678-86212010000300007. Acesso em: 01 mar. 2018.

SIQUEIRA, T. A.; ARAÚJO, R. de S. (2014). Programas de habitação social no Brasil. Perspectivas Online : Humanas e Sociais Aplicadas, 01 July 2014, Vol.4(10),45-54. Disponível em: https://doaj.org/article/d3613697c97747beb485ae60c44835ec. Acesso em 01 mar. 2018.

VILLA, S. B. et al. (2017). Co-production and Resilience in a Brazilian Social Housing: the case of Shopping Park Neighbourhood. 33 PLEA International Conference - Design to Thrive, Edinburgh, v. 3, julio. 